\title{
THE ASSESSMENT OF ENVIRONMENTAL AND HEREDITARY FACTORS IN OBESE PATIENTS
}

V.Lobashova, A.Shepelkevich, J.Dydyshko, A.Sosedkova

Belorussian State Medical University, Minsk, Belarus

\section{OBJECTIVES}

The rapidly increasing epidemic of obesity is one of the most challenging dilemmas facing endocrinologists all over the world today. The scale of the obesity problem has a number of serious consequences for individuals and for government health systems.

The aim of the research was to reveal and assess the interaction between environmental and hereditary factors in obese patients seeking for weight loss.

\section{METHODS}

We analyzed the anamnesis of 134 overweight and obese patients, having asked to endocrinologist for losing weight (20 men and 112 women). The mean age of the respondents was $45,78 \pm 8,76$ years.

Heritability of obesity was determined according to family history of obesity, anamnesis of diabetes in relatives, childhood appearance of excess body weight. The environmental changes included eating habits, level of physical activity and water regime of participants.
134 patients

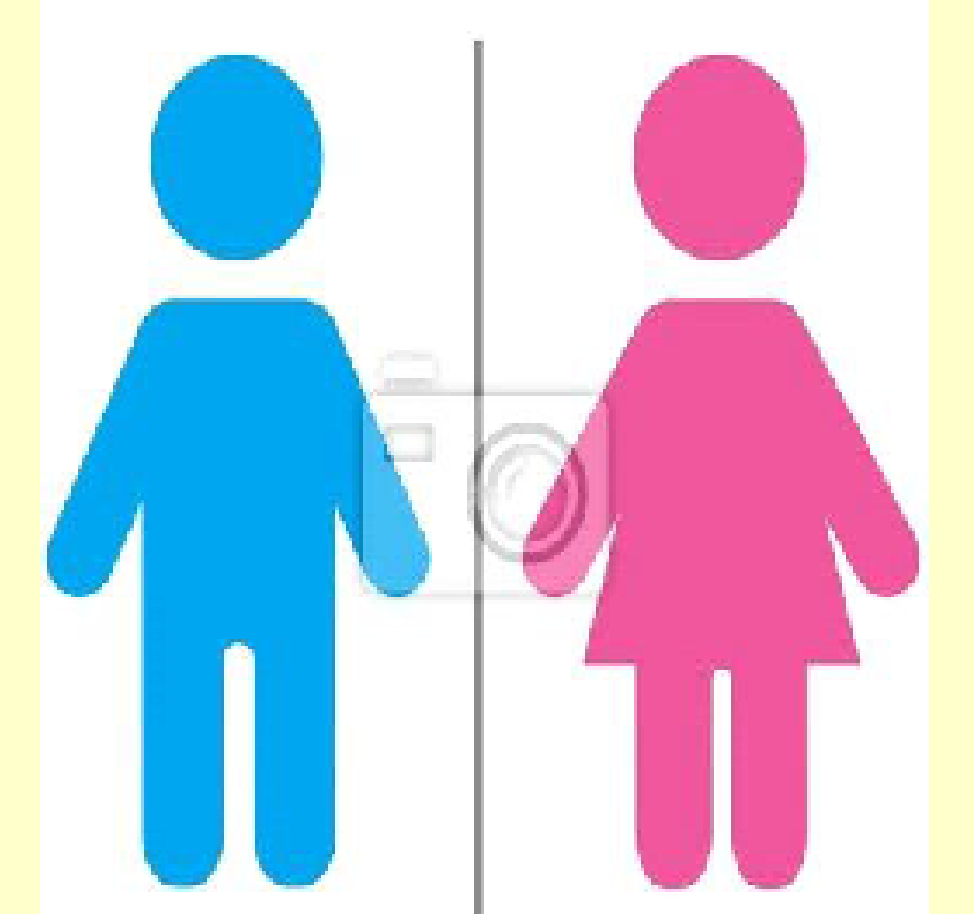

$15 \% \quad 85 \%$
Environmental factors:

1.eating habits

2.level of physical activity

3.water regime

\section{Obesity prevalence}

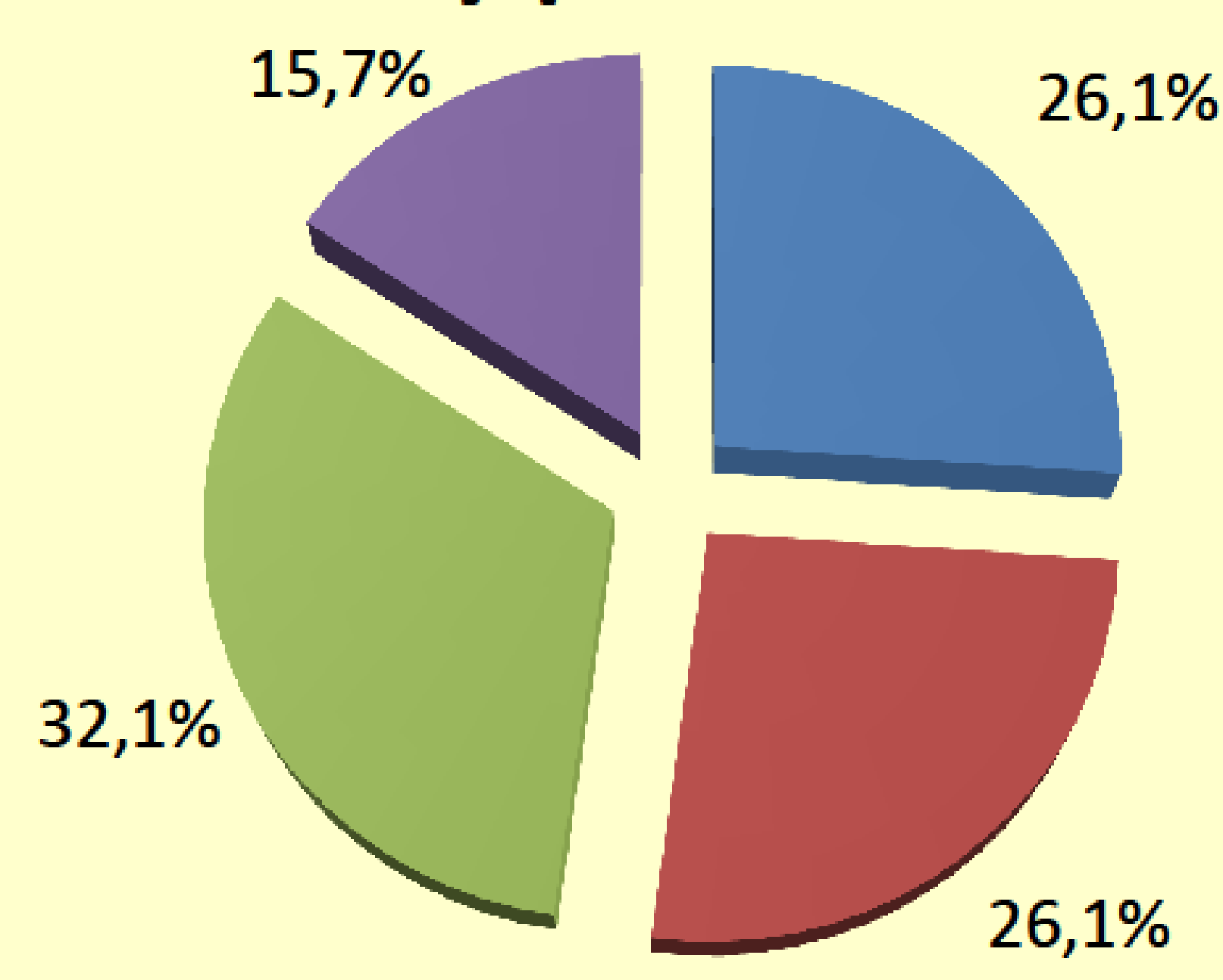

च obesity III $\quad$ obesity II $\quad$ obesity I $\quad$ overweight

\section{RESULTS}

The assessment of the hereditary factors of obesity revealed that $76,5 \%$ (101 person) had a family history of obesity: $59,7 \%$ (80 patients) mentioned excess body weight on the maternal line and $40,3 \%$ (54 patients) for father's relatives. Diabetes was diagnosed in 14,9\% (20 persons) - on the maternal line and in $9,7 \%$ (13 persons) on the fatherly line. $41 \%$ of respondents ( 55 patients) remarked childhood obesity in themselves.

\section{Hereditary factors:}

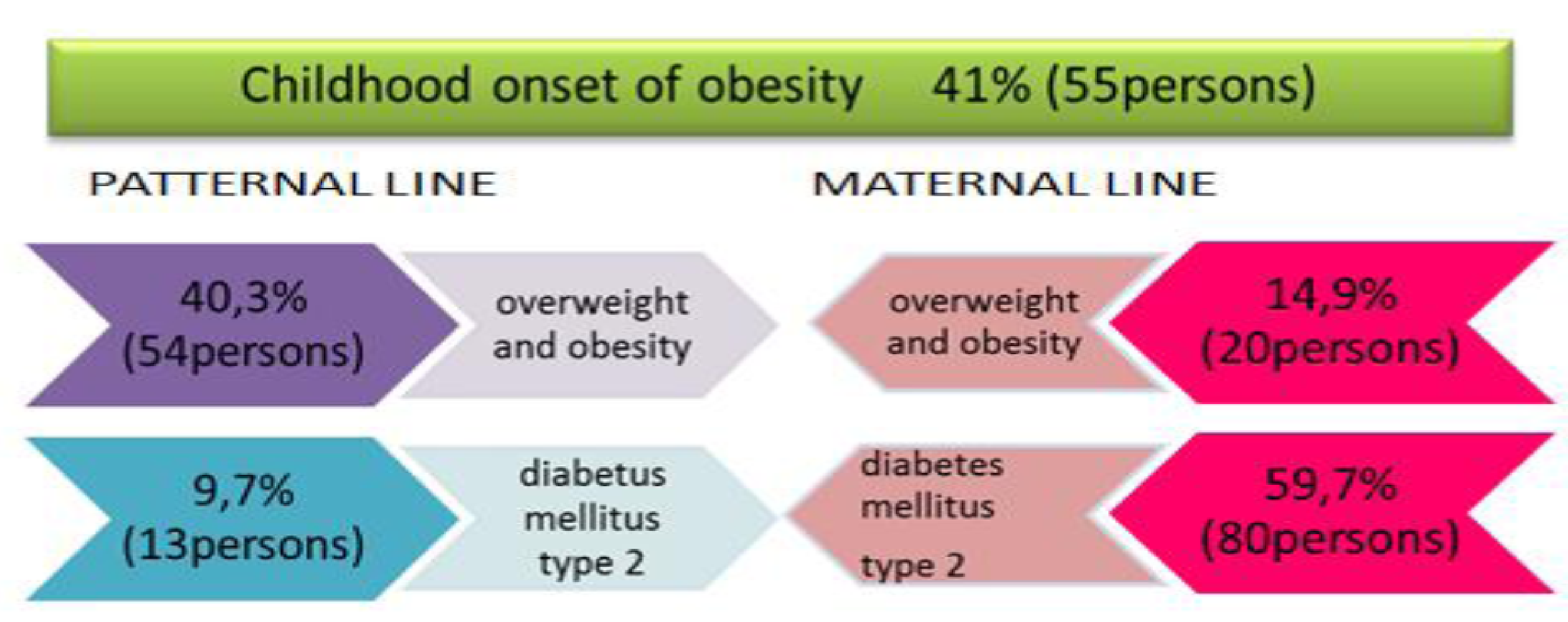

\section{Environmental factors:}

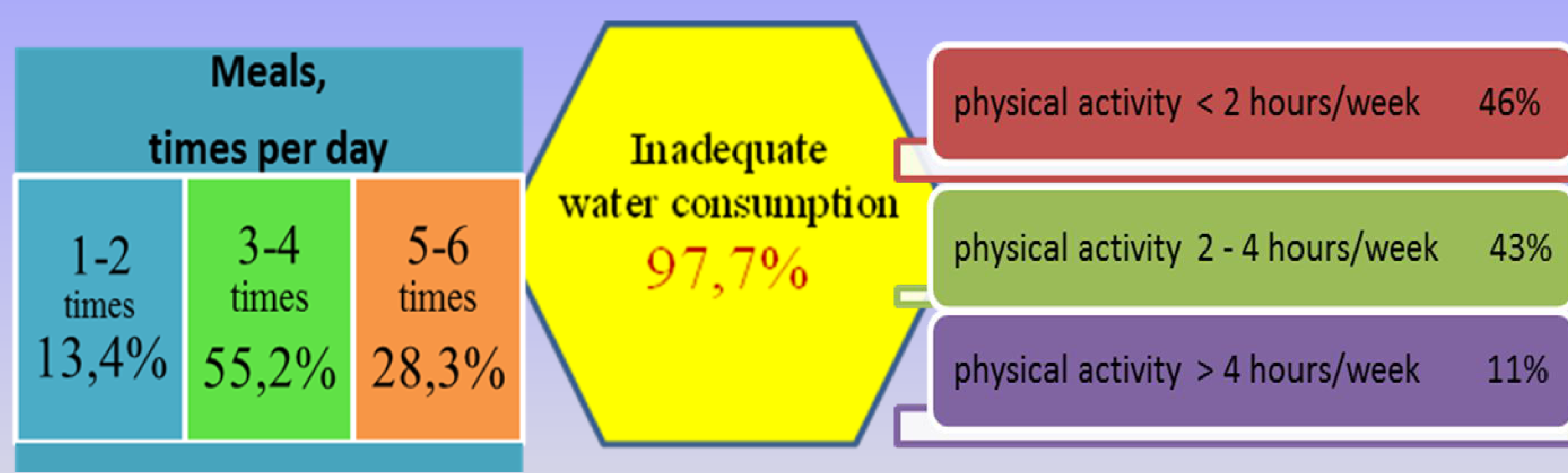

The analysis of environmental factors showed that $71,7 \%$ of respondents skipping meals during the day, $13,4 \%$ (18 persons) had only 1 meal, 55,2 \% (74 persons) had 2-3 meals per day. Everyday moderate activity 30 minutes or more described only $11 \%$ of respondents, physical activity 30 minutes or less 3 days a week described $46 \%$ of patients, 30 minutes of activity 5-6 times a week $43 \%$ patients. The vast majority of patients $97,7 \%$ drank less than 2 liters of water per day.

\section{CONCLUSIONS}

The occurrences of obesity relatives was $59,7 \%$ on the maternal line, $40,3 \%$ on the paternal line. Interaction with environment factors related to low physical activity and inadequate water consumption. 